Subscriber access provided by Lib4RI - Library for Eawag, Empa, PSI \& WSL

\title{
Article
}

\section{Highly carboxylated cellulose nanofibers via succinic anhydride esterification of wheat fibers and facile mechanical disintegration}

Houssine Sehaqui, Karol Kulasinski, Numa Pfenninger, Tanja Zimmermann, and Philippe Tingaut

Biomacromolecules, Just Accepted Manuscript • DOI: 10.1021/acs.biomac.6b01548 • Publication Date (Web): 29 Nov 2016

Downloaded from http://pubs.acs.org on December 12, 2016

\section{Just Accepted}

"Just Accepted" manuscripts have been peer-reviewed and accepted for publication. They are posted online prior to technical editing, formatting for publication and author proofing. The American Chemical Society provides "Just Accepted" as a free service to the research community to expedite the dissemination of scientific material as soon as possible after acceptance. "Just Accepted" manuscripts appear in full in PDF format accompanied by an HTML abstract. "Just Accepted" manuscripts have been fully peer reviewed, but should not be considered the official version of record. They are accessible to all readers and citable by the Digital Object Identifier (DOI®). "Just Accepted" is an optional service offered to authors. Therefore, the "Just Accepted" Web site may not include all articles that will be published in the journal. After a manuscript is technically edited and formatted, it will be removed from the "Just Accepted" Web site and published as an ASAP article. Note that technical editing may introduce minor changes to the manuscript text and/or graphics which could affect content, and all legal disclaimers and ethical guidelines that apply to the journal pertain. ACS cannot be held responsible for errors or consequences arising from the use of information contained in these "Just Accepted" manuscripts. 


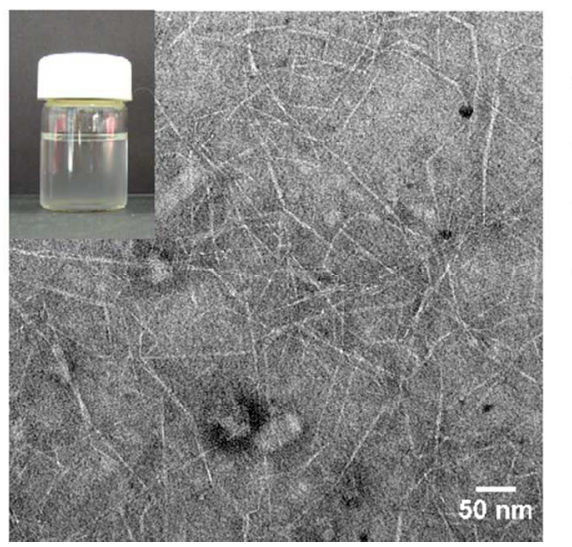

- Diameter: $5 \mathrm{~nm}$

- Carboxyl content: $3.8 \mathrm{mmol} \mathrm{g}^{-1}$

- High molar mass

- Facile isolation

- Efficient removal of lead from aqueous solution

$171 \times 69 \mathrm{~mm}(150 \times 150 \mathrm{DPI})$ 


\title{
Highly carboxylated cellulose nanofibers via
}

\section{succinic anhydride esterification of wheat fibers}

\section{and facile mechanical disintegration}

\author{
H. Sehaqui ${ }^{* \dagger}{ }^{\dagger}$ K. Kulasiński, ${ }^{*}$ N. Pfenninger, ${ }^{\S}$ T. Zimmermann ${ }^{\dagger}$ and P. Tingaut ${ }^{\dagger}$ \\ $\dagger$ Empa, Swiss Federal Laboratories for Materials Science and Technology, Applied Wood Materials \\ Laboratory. Überlandstrasse 129, CH-8600, Dübendorf, Switzerland. E-mail: \\ houssine.sehaqui@empa.ch; Tel.: +41 587656118. Fax: +41 587651122, † Department of \\ Geochemistry, Lawrence Berkeley National Laboratory, Berkeley CA, United States, § Eawag, \\ Überlandstrasse 133, CH-8600, Dübendorf, Switzerland. \\ * To whom correspondence should be addressed. Tel.: +41 5876561 18. Fax: +41 5876540 07. E- \\ mail: houssine.sehaqui@empa.ch (H. Sehaqui).
}

\begin{abstract}
We report herein the preparation of 4-6 $\mathrm{nm}$ wide carboxyl-functionalized cellulose nanofibers (CNF) via the esterification of wheat fibers with cyclic anhydrides (maleic, phtalic and succinic) followed by an energy-efficient mechanical disintegration process. Remarkable results were achieved via succinic anhydride esterification which enabled CNF isolation by a single pass through the microfluidizer yielding a transparent and thick gel. These CNF carry the highest content of carboxyl groups ever reported for native cellulose nanofibers $\left(3.8 \mathrm{mmol} \mathrm{g}^{-1}\right)$. Compared to conventional carboxylated cellulose nanofibers prepared via Tempo-mediated oxidation of wheat fibers, the present esterified CNF display a higher molar-mass and a better thermal stability. Moreover, highly carboxylated CNF from succinic anhydride esterification were effectively integrated into paper filters for the removal of lead from aqueous solution and are potentially of interest as carrier of active molecules, or as transparent films for packaging, biomedical or electronic applications.
\end{abstract}


KEYWORDS: Cellulose nanofibers, carboxyl groups, high molar mass, lead adsorption, rheology.

\section{Introduction}

Cellulose nanofibers (CNF) belong to an emerging class of plant-based nanomaterials combining natural abundance, low environmental impact, large surface area and aspect ratio, lightweight, high strength, and functionalizability. ${ }^{1,2}$ Recent advances made in disintegration processes as well as large array of CNF functionalization possibilities significantly contributed to the development of CNF materials in both academia and industry and fostered promising applications in areas such as energy, environment, and biomedicine..$^{3-10}$

In the pioneer work of Turbak in the early 1980's when a high-shear homogenizer disintegrated wood pulp to $\mathrm{CNF}$, the process was energy intensive requiring 20 consecutive passes through the mechanical device, and resulted in rather coarse nanofibers of 25-100 nm. ${ }^{1}$ In subsequent works, it was shown that pretreating the pulp considerably cut down the mechanical disintegration energy and produced thinner nanofibers with more homogenous distribution possibly carrying new functionalities on their surfaces..$^{3-5,11}$ Amongst these pretreatments, cellulose oxidation using 2,2,6,6-Tetramethyl-1-piperidinyloxy free radical (Tempo) provided the smallest nanofibrils of 3-5 $\mathrm{nm}$ in diameter, at a low disintegration energy due to the repulsion of negatively charged carboxyl groups at the fibrils surface. ${ }^{5}$ This led to new application possibilities including transparent films for packaging and electronic applications, ${ }^{12,13}$ template for functional polymers and bioactive molecules, ${ }^{8,10}$ as well as sorbents of heavy metal ions, radioactive species and dies. ${ }^{9,14,15}$ However, besides the toxicity of Tempo, the oxidation conducted at basic $\mathrm{pH}$ conditions leads to CNF having a low molar mass, which is detrimental to the ductility and toughness of CNF films. ${ }^{5,16,17,44}$ Low molar mass $\mathrm{CNF}$ can be prevented when the oxidation is done under neutral $\mathrm{pH}$, but the resulting carboxyl content of CNF is low $\left(1.7 \mathrm{mmol} \mathrm{g}^{-1}\right.$ at $\mathrm{pH} 10$ vs $0.8 \mathrm{mmol} \mathrm{g}^{-1}$ at $\left.\mathrm{pH} 6.8\right) .{ }^{16}$ The development of alternative pretreatment methods for the preparation of highly carboxylated cellulose nanofibers of high molar mass is thus interesting as it could widen property and application possibilities for CNF-based materials. 
In a recent work by Iwamoto et al., carboxyl-functionalized CNF with a diameter of $3 \mathrm{~nm}$ and a maleic acid content of $18.8 \mathrm{wt} \%$ equivalent to a carboxyl content of $1.9 \mathrm{mmol} \mathrm{g}^{-1}$ were prepared via the mechanical disintegration of wood flour esterified with maleic anhydride. ${ }^{18}$ In the present work, we explore the esterification of cellulose with various cyclic anhydrides (maleic, phtalic and succinic anhydrides) aiming to produce highly carboxylated CNF. Morphological, chemical and thermal characteristics of the nanofibers were investigated, as well as rheological properties of CNF aqueous suspension. These properties were compared to those of Tempo-oxidized CNF. The highest carboxyl content ever reported for CNF was reached and possible responsible mechanism were discussed based on molecular dynamic simulations. We finally demonstrate good performance of highly carboxylated CNF incorporated in paper filters for the removal of lead from contaminated water.

\section{Materials and methods:}

Materials. Wheat fibers with a particle size of $30 \mu \mathrm{m}$ and having the tradename of "JELUCEL WF 30" was obtained from Jelu-Werk Josef Ehrler GmbH \& Co (Germany). These fibers are lignin free and have cellulose, xylan and glucomannan contents of $76 \%, 23 \%$ and $1 \%$, respectively. The sugar analysis was carried out at University of Hamburg (Zentrum für Holzwirtschaft) according to a procedure described by Wilför et al. ${ }^{46}$ Maleic, phtalic and succinic anhydrides with a purity $>98 \%$ were purchased from Merck and used as received without further purification. Pyridine (purity $>99 \%$ ) and dimethylformamide (DMF; purity $>99.5 \%$ ) were purchased from Roth chemicals (Switzerland). $\mathrm{Pb}\left(\mathrm{NO}_{3}\right)_{2}$ was supplied by Riedel de Haën AG (Germany).

Preparation of carboxyl-functionalized cellulose nanofibers. A round bottom flask containing 1 liter of DMF, $120 \mathrm{~g}$ of wheat fibers previously dried over a silica gel, $2.6 \mathrm{~mol}$ of the anhydride (21.5 mmol of the anhydride per gram of the fibers) and $1 \mathrm{ml}$ of pyridine was heated to $90{ }^{\circ} \mathrm{C}$ for 5 hours under magnetic stirring at $500 \mathrm{rpm}$. The wheat fibers were thereafter thoroughly washed with deionized water, neutralized to the carboxylate form using $1 \mathrm{M} \mathrm{NaOH}$ solution, dialysed against deionised water until neutral $\mathrm{pH}$ and finally disintegrated within a microfluidizer (M-110EH, Microfluidics Ind., Newton, MA) equipped with 400, 200 and $75 \mu \mathrm{m}$ chambers at a pressure of ca. 1200 bars and room temperature. The disintegration was 
continued until gel formation (assessed visually). When a strong gel was obtained after the first pass using the big interaction chambers of the microfluidizer (400 and $200 \mu \mathrm{m}$ ), it could not pass thereafter through the small chambers $(200$ and $75 \mu \mathrm{m})$ and was therefore discarded and replaced by a gel which passed solely through the small chambers. Carboxylated cellulose nanofibers obtained are denoted MCNF, PCNF, SCNF when maleic, phtalic and succinic anhydrides were reacted with wheat fibers, respectively. For comparison, Tempo-oxidised CNF denoted TOCNF were prepared from wheat fibers according to the method reported by Saito et al. by using $10 \mathrm{mmol} \mathrm{g}^{-1}$ of $\mathrm{NaClO}$ and conducting the reaction at a $\mathrm{pH}$ of $10 .^{5}$

Characterization of carboxyl-functionalized cellulose nanofibers. The morphology of the nanofibers was investigated by means of scanning electron microscopy (SEM) in a FEI Nova NanoSEM 230 microscope. A drop of the CNF suspension at $0.1 \%$ was dried under vacuum and the CNF were thereafter sputtered with a platinum layer of about $7.5 \mathrm{~nm}$ under $\mathrm{Ar}$ at 0.05 mbar (BAL-TEC AG, Liechtenstein). TEM investigations were carried out on a JEOL $2200 \mathrm{FS}$ at $200 \mathrm{kV}$, using plasma-treated copper grids and staining CNF with uranyl acetate solution (30 seconds in $1 \%$ aqueous solution). Specific surface area of the nanofibers was determined according to a multipoint BET method by nitrogen physisorption on a surface area and pore size analyzer (Coulter SA3100) by drying CNF suspension beforehand under supercritical $\mathrm{CO}_{2}$ in order to preserve the structure. ${ }^{34} \mathrm{X}$-Ray Diffraction analysis (XRD) was done in a PANalytical X'Pert PRO $\theta-2 \theta$ MPD system ( $\mathrm{Cu}-\mathrm{K} \alpha$ radiation, $1.5418 \AA)$. The diffraction patterns were recorded from $5^{\circ}$ to $40^{\circ}$ in $2 \theta$ with an angular step interval of $0.025^{\circ}$. From XRD spectra, the crystallinity index was determined according to the Segal method. ${ }^{35}$ Fourier transform infrared (FTIR) spectra were recorded using a FTS 6000 spectrometer (Portmann Instruments AG, Biel-Benken, Switzerland) between 4000 and $600 \mathrm{~cm}^{-1}$ with a resolution of $4 \mathrm{~cm}^{-1}$ and 32 scans. All FTIR spectra were normalized with respect to the peak located at $897 \mathrm{~cm}^{-1}$ corresponding to the $\mathrm{C}-\mathrm{O}-\mathrm{C}$ stretching vibration of the cellulose $\beta-(1 \rightarrow$ 4)-glucosidic linkage. ${ }^{36}$ Carboxylate content was determined by conductometric titration method using $0.05 \mathrm{M} \mathrm{NaOH}$ solution. ${ }^{37}$ Viscosity-average degree of polymerization $\left(\mathrm{DP}_{\mathrm{v}}\right)$ was evaluated according to the capillary viscosimeter method using cupriethylenediamine as 
solvent. The intrinsic viscosity was converted to $\mathrm{DP}_{\mathrm{v}}$ according to the Staudinger-Mark-Houwink equation, $[\eta]=\mathrm{K} \times \mathrm{M}^{\mathrm{a}}{ }^{38}$ This method has been developed for cellulose, but has also been used elsewhere to estimate the D.P of negatively charged cellulose (carboxylated cellulose). ${ }^{16}$ Thermogravimetric analysis (TGA) was used to investigate thermal properties of CNF. Experiments were performed in a TGA7 instrument from Perkin Elmer under helium flow $\left(25 \mathrm{ml} \mathrm{min}^{-1}\right)$ from $30{ }^{\circ} \mathrm{C}$ to $450{ }^{\circ} \mathrm{C}$ at a rate of $20 \mathrm{~K} \mathrm{~min}^{-1}$ with maintaining the temperature at $100{ }^{\circ} \mathrm{C}$ for $15 \mathrm{~min}$ to remove adsorbed moisture. The temperature at a weight loss of $5 \%$ was taken as the temperature of onset degradation $\left(\mathrm{T}_{\text {onset }}\right)$. Light Transmittance of CNF was measured using a UV-Visible spectrophotometer (Shimadzu UV3600) by placing the CNF suspension at $0.1 \mathrm{wt} \%$ in a cuvette and recording the transmittance in the 230-800 $\mathrm{nm}$ wavelength range. Rheological measurements of CNF suspension at $1 \mathrm{wt} \%$ were performed with a rotational rheometer with concentric cylinder geometry (Rheolab QC, CC39 geometry, $1.64 \mathrm{~mm}$ gap size, Anton Paar, Austria) at $25{ }^{\circ} \mathrm{C}$ in controlled shear rate mode by varying the shear rate from 0.1 up to $1000 \mathrm{~s}^{-1} . \zeta$-potential measurements were performed on solutions at $\sim 0.1 \mathrm{wt} \%$ using a Zetasizer NanoZS instrument (Malvern, UK). The zetapotentials were calculated from electrophoretic mobility using a formula valid for spherical particles, and the data were used for comparative purpose only. To redisperse the CNF, frozen suspensions in liquid nitrogen were lyophilized and immersed in water at a given concentration, then sonicated at an amplitude of 55\% for 1 minute (Branson digital sonifier, model 102C).

Atomistic model. The all-atom Molecular Dynamics (MD) simulations were carried out to determine transport properties of the anhydrides in bulk DMF solution and in the vicinity of crystalline cellulose. The force field parameters, in Gromos 53a6 standard, of the anhydrides MD models have been obtained using a multistep process where quantum mechanical calculations are combined with a knowledge-based approach, by optimizing at the HF/STO-3G level and then re-optimizing at the B3LYP/6-31G level of theory in implicit water. ${ }^{39}$ The partial charges of the anhydrides have been obtained by fitting the electrostatic potential using Kollmann-Singh scheme. The structure of $\mathrm{I}_{\beta}$ crystalline cellulose has been generated ${ }^{40}$ based on most recent X-ray and neutron diffraction data. ${ }^{41}$ 
The anhydrides are solvated in bulk DMF with 1:5 ratio in periodic box of approx. $1000 \mathrm{~nm}^{3}$ (same experimental ratio). The initial structures are energy-minimized using steepest descent and conjugated gradient methods and are subsequently equilibrated at $293 \mathrm{~K}$ and at 1 bar. The mean square displacement curves as well as the density profiles are extracted from $10 \mathrm{~ns}$ simulations.

Preparation of paper filters. Pulp residue, a waste product from pulp and paper industry described elsewhere ${ }^{42}$ was used for the preparation of paper filters according to our previously reported method. ${ }^{37-38}$ The pulp residue is emanating from a dissolving pulp process and has a high cellulose content of $95 \%$ and a hemicellulose content of $4.75 \% .500 \mathrm{mg}$ dry weight of the pulp was mixed with $25 \mathrm{mg}$ of the CNF while the total volume being $250 \mathrm{ml}$. The mixture was thereafter filtered on top of a membrane with pore size of $0.65 \mu \mathrm{m}$ (DVPP, Millipore) and internal diameter of $8 \mathrm{~cm}$. The cake thus formed was dried in a sheet dryer at $93{ }^{\circ} \mathrm{C}$. The reference paper filter was prepared similarly without using CNF. The paper filter performance in terms of lead removal was evaluated according to a previously reported method ${ }^{43}$ whereby $150 \mathrm{ml}$ of the lead solution was filtered on top of the paper filter using a dead-end Sterlitech device (HP4750, Kent, USA) having an active area of $1460 \mathrm{~mm}^{2}$. To ensure that the filtration device does not retain lead, a blank solution was filtered on the device without the use of the paper filter. The concentration of lead in solution was determined by Inductively coupled plasma mass spectrometry (ICP-MS).

\section{Result and discussion}

Wheat fibers was selected herein as raw material for the preparation of carboxylated CNF since it was available in dry form with a particle size of only $30 \mu \mathrm{m}$ and does not require any solvent-exchange prior to the esterification reaction. Esterification of cellulose with cyclic acid anhydrides opens the cycle and results in terminal carboxyl functions attached to the cellulose as schematically shown in Figure 1. Esterified wheat fibers in water at $1 \mathrm{wt} \%$ was mechanically disintegrated by passing it through the microfluidizer until gel formation, which is characteristic of successful fibrillation. ${ }^{1}$ While most samples required many passes for the fibrillation, succinic anhydride-modified wheat fibers required only one pass to yield a strong SCNF gel (reasons to be discussed later). Scanning electron 
micrographs of the CNF attest the successful fibrillation process and displayed the typical network structure of CNF for all modifications envisaged in this work (see supporting information S1). Transmission electron micrographs of the CNF in Figure 2 further show their homogeneous distribution and allow estimating their diameter which was in the range 4-6 nm (Table 1, higher TEM magnifications in supporting information S2). The diameter of esterified CNF is similar to that of Tempo-oxidized CNF (TOCNF) prepared either from the same source (Table 1), or from never-dried cotton and wood pulp, ${ }^{19}$ and is smaller than CNF prepared according to the enzymatic pretreatment method which are typically 5-20 $\mathrm{nm}$ in diameter after 8-12 passes through the homogenizer. ${ }^{4,17}$ Along with their small diameter, the CNF display a large specific surface area $\left(\mathrm{S}_{\mathrm{BET}}\right)$ of $290-370 \mathrm{~m}^{2} \cdot \mathrm{g}^{-1}$ (Table 1).

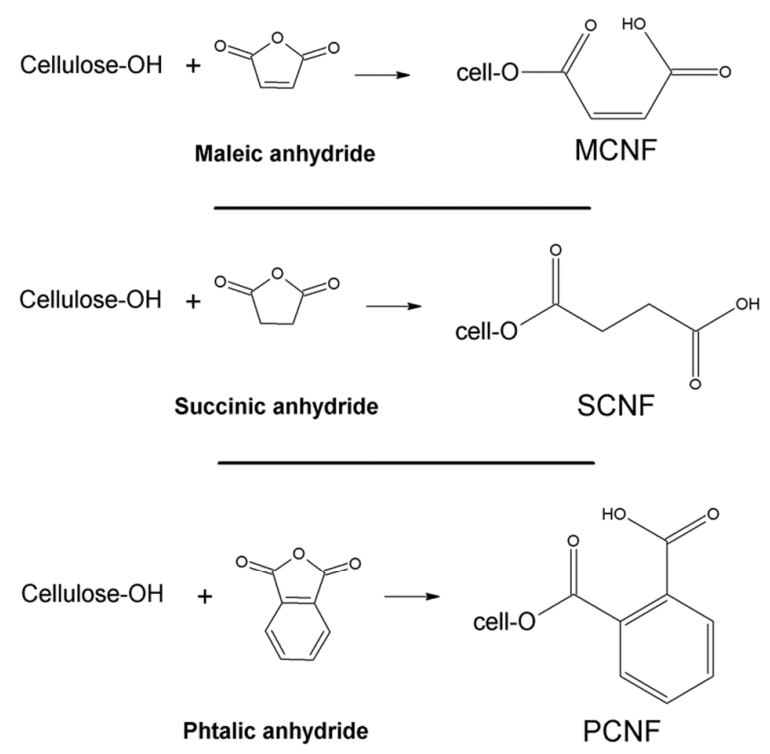

Figure 1. Reaction scheme of cellulose with cyclic anhydrides

Table 1. Characteristics of wheat fibers, esterified CNF and Tempo-oxidized CNF. Passes expressed as " $\mathrm{X}+\mathrm{Y}$ " refer to the number of passes through the microfluidizer having the $400 \mu \mathrm{m} / 200 \mu \mathrm{m}$ chambers (X) and $200 \mu \mathrm{m} / 75 \mu \mathrm{m}$ chambers (Y). Values in parentheses are standard errors.

\begin{tabular}{|c|c|c|c|c|c|}
\hline & Wheat fibers & $\mathrm{MCNF}$ & PCNF & SCNF & TOCNF \\
\hline Passes & - & $5+5$ & $3+1$ & $0+1$ & $5+5$ \\
\hline Diameter (nm) & - & $4.4(1.0)$ & $6.1(1.7)$ & $5.4(1.5)$ & $5.7(1.5)$ \\
\hline $\mathrm{S}_{\mathrm{BET}}\left(\mathrm{m}^{2} \mathrm{~g}^{-1}\right)$ & - & 295 & 320 & 295 & 370 \\
\hline $\mathrm{COOH}$ content $\left(\mathrm{mmol} \mathrm{g}^{-1}\right)$ & $0.04 \quad(0.00)$ & $0.9(0.04)$ & $1.0(0.02)$ & $3.8(0.2)$ & $1.3(0.06)$ \\
\hline
\end{tabular}



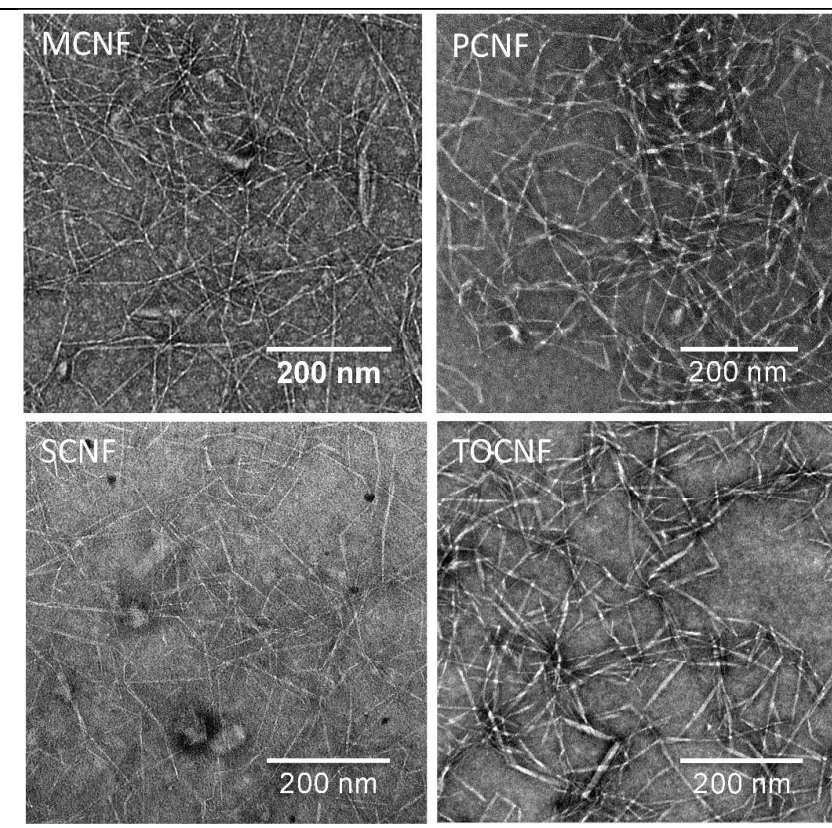

Figure 2. TEM micrographs of esterified CNF and TOCNF.

The carboxyl functions of the esterified CNF were first identified by FTIR (Figure 3.a) which resulted in a peak at $\sim 1725 \mathrm{~cm}^{-1}$ characteristic of the $\mathrm{C}=\mathrm{O}$ stretching vibration of the ester linkage, and a peak at $1570-1600 \mathrm{~cm}^{-1}$ attributed to the carboxylate groups (conjugated form). Negatively charged surface of carboxylated CNF is apparent from their zeta-potential values (Table 1). Surface charge of carboxylated nanofibers $(-43$ to $-50 \mathrm{mV})$ is higher in absolute value compared to the initial wheat fibers surface charge $(-32.2 \mathrm{mV})$. 

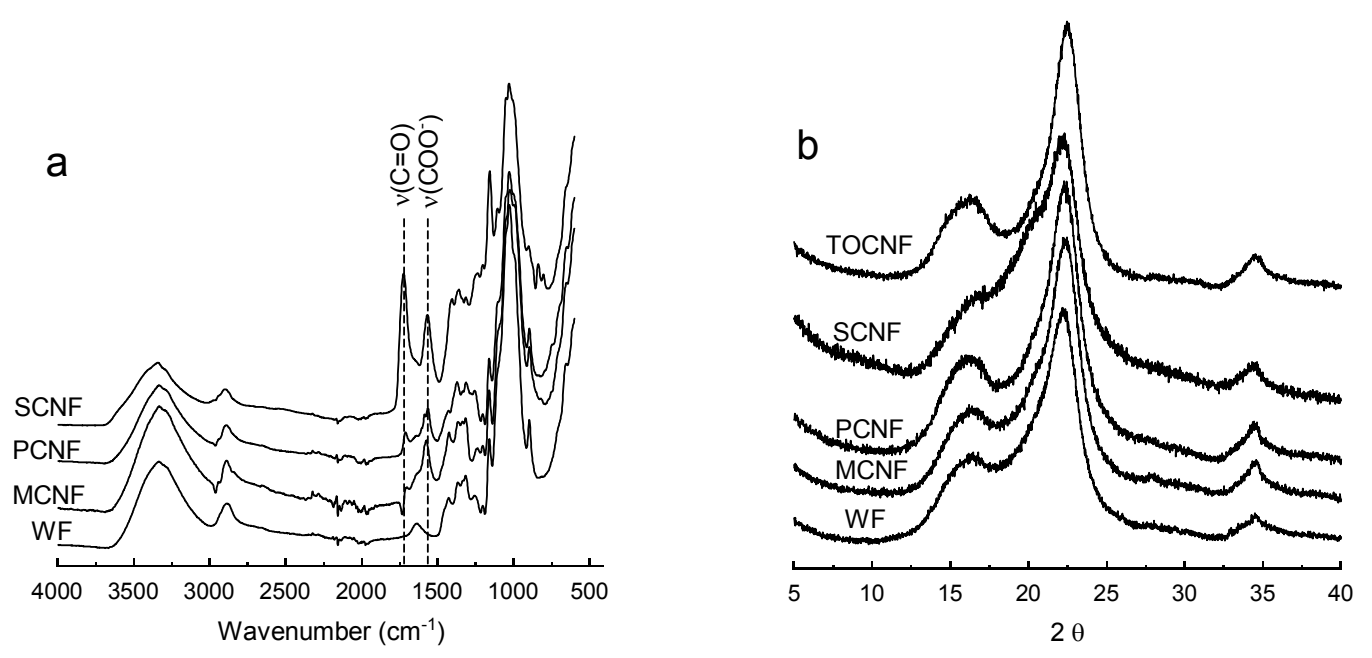

Figure 3. a. FTIR spectra of original wheat fibers (WF) and esterified CNF. b. XRD spectra of original wheat fibers (WF), esterified CNF, and TOCNF.

Carboxyl groups of the nanofibers were thereafter quantified by conductometric titration (Table 1), which gave a much higher value for SCNF $(3.8 \mathrm{mmol} \mathrm{COOH}$ per gram of nanofibers) compared to other nanofibers $\left(0.9-1.3 \mathrm{mmol} \mathrm{g}^{-1}\right)$. Hence, the high carboxyl group content of SCNF explains their facile and energy-efficient isolation, as well as the intense peak in their FTIR spectra. The carboxyl content of SCNF is about twice as high as that of Tempooxidized CNF $\left(1.7 \mathrm{mmol} \mathrm{g}^{-1}\right),{ }^{20}$ periodate-oxidized CNF $\left(1.75 \mathrm{mmol} \mathrm{g}^{-1}\right),{ }^{21}$ and esterified CNF with maleic anhydride $\left(1.9 \mathrm{mmol} \mathrm{g}^{-1}\right){ }^{18}$ The corresponding degree of substitution (DS) of SCNF is 0.67 (Table 1) and this is higher than the degree of oxidation of carboxylated cellulose nanocrystals prepared via ammonium persulfate oxidation (0.11-0.19). ${ }^{22}$ Furthermore, for TOCNF from both softwood and hardwood, a carboxyl content of $1.7 \mathrm{mmol} \mathrm{g}^{-1}$ corresponds to the conversion of all the C6 primary hydroxyl groups of cellulose exposed at the nanofibril surfaces to carboxyl groups. ${ }^{20}$ It is therefore expected that secondary hydroxyl groups in the $\mathrm{C} 3$ and possibly $\mathrm{C} 2$ positions of cellulose at the nanofibril surface have participated in the reaction with succinic anhydride giving the highest carboxyl content ever reported for native cellulose nanofibers. The characteristic diffraction peaks of native cellulose at $2 \theta$ angles of $14.8^{\circ}, 16.6^{\circ}, 22.3^{\circ}$ and $34.4^{\circ}$, corresponding to $1-10,110,200$ and 004 lattices, ${ }^{23}$ are observed for esterified and TOCNF (Figure 3.b). However, the crystallinity index (CI) is 
the lowest for SCNF (Table 1) with a less remarked nadir at $19^{\circ}$ attributed to a reduced number of hydrogen bonds after the esterification of secondary hydroxyl groups at the fibrils surface rendering it less crystalline. Nevertheless, the fibril structure is preserved despite the high DS of SCNF as evidenced from SEM / TEM micrographs and surface area measurements. It should be noted that some changes in the crystalline structure in microfibril (decrease in the (110) reflection intensity) may be observed after oxidation and mechanical treatments of cellulose, as reported by $\mathrm{Su}$ et al. ${ }^{45}$ The yield of the reaction with succinic anhydride is $88 \%$ attesting a minor fiber loss during the reaction, washing and recovery steps. The viscosityaverage degree of polymerization $\left(\mathrm{DP}_{\mathrm{v}}\right)$ of esterified $\mathrm{CNF}$ is $725-960$, and this is much higher than $\mathrm{DP}_{\mathrm{v}}=140$ of TOCNF (Table 1), attesting a lesser degradation of the cellulose chains during carboxylated CNF preparation via esterification with cyclic anhydrides. $\mathrm{DP}_{\mathrm{v}}$ results and TEM observations (see also supporting information S2) suggest that esterified CNF are longer than TOCNF knowing that the $\mathrm{DP}_{\mathrm{v}}$ correlates with the CNF length. ${ }^{24}$

Possible mechanisms responsible for the high carboxyl content of SCNF were investigated via molecular dynamics simulation. First, the diffusion coefficients of the anhydrides in bulk are found by determination of the mean square displacement curves (Figure 4.a). The diffusion coefficient, proportional to the slope, reveals the important differences between the anhydrides. Namely, maleic anhydride is characterized by the highest diffusion coefficient $\left(1.28 \times 10^{-5} \mathrm{~cm}^{2} \mathrm{~s}^{-1}\right)$ whereas succinic and phthalic anhydrides are diffusing slower $\left(0.93 \times 10^{-5} \mathrm{~cm}^{2} \mathrm{~s}^{-1}\right.$ and $0.8 \times 10^{-5} \mathrm{~cm}^{2} \mathrm{~s}^{-1}$, respectively). The differences in diffusion coefficients are strongly related to the size and mass of the anhydrides, which in turn explains the highest mobility of maleic anhydride that is the smallest by mass and volume.
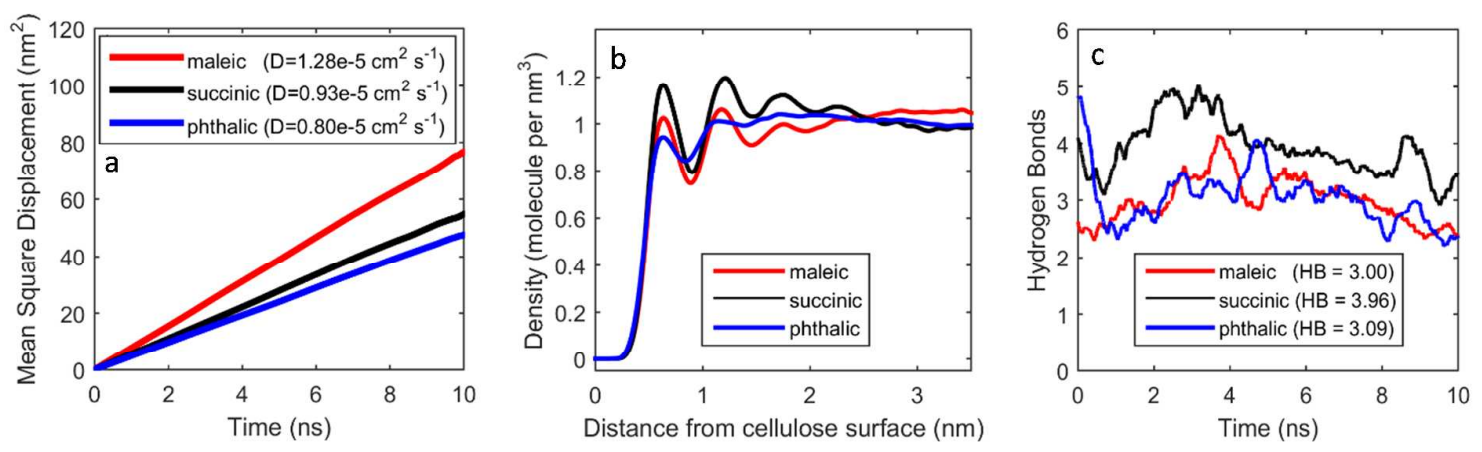
Figure 4. Comparison of the molecular properties of the three anhydrides in DMF solution: maleic (red), succinic (black), and phthalic (blue). a. Mean Square Displacement curves, b. density near cellulose surface, c. number of hydrogen bonds formed with cellulose.

In order to quantify the molecules behaviour in the vicinity of the crystalline cellulose, the three solutions are placed between the cellulose (110) surfaces. It is observed that, when averaged over time (10 ns), the anhydrides form layers next to the surface which can be quantified as density profiles (Figure 4.b). Considering the first layer (positioned at $0.63 \mathrm{~nm}$ from the surface) to be the most reactive, succinic anhydride is found to be attracted by cellulose surface more than the other anhydrides. The likelihood to be at the cellulose surface is strongly related to the formation of hydrogen bonds between the cellulose residues and anhydrides (Figure 4.c). In effect, succinic molecules form on average 3.96 hydrogen bonds which is remarkably more than maleic (3.0) and phthalic (3.09) anhydrides. We conclude that the higher overall reaction rate of succinic anhydride cannot be due to difference in the mobility of its molecules but rather due to its preferential adsorption at the cellulose interface.

Thermal properties of the CNF were evaluated by thermogravimetric analysis in an inert atmosphere (Figure 5). As compared to the pristine wheat fibers, thermal properties of the carboxylated CNF display lower thermal stability indicated by a lower temperature at the onset of thermal degradation ( $\mathrm{T}_{\text {onset; }}$ see Table 1), and this might be attributed to higher surface area of CNF that contributes to lower resistance to thermal degradation. When comparing esterified CNF and Tempo-oxidised CNF, a higher thermal stability is observed for the former. During thermal degradation of cellulose, depolymerization of the chains and formation of low molar-mass oligosaccahrides and sugars occurs. ${ }^{25}$ It is therefore expected that higher $\mathrm{DP}_{\mathrm{v}}$ of esterified CNF contribute to their better thermal stability as compared to TOCNF. In a study by Chen et al., cellulose nanocrystals produced using concentrated organic acids (including maleic acid) had substantially higher thermal stability than those produced using mineral acids such as sulfuric, phosphoric, and hydrochloric acids. ${ }^{26}$ 
Figure 5. TGA weight loss of original wheat fibers (WF), esterified CNF and TOCNF.

We further characterized properties of the aqueous CNF suspensions (Figure 6). These have a high transmittance $(\% \mathrm{~T})$ in the visible range due to their nanosize which limits scattering of visible light (Figure 6.a). It is accepted that the \% $\mathrm{T}$ increased with the carboxyl group content of carboxylated CNF suspensions. ${ }^{5,21}$ Saito et al. showed that the $\% \mathrm{~T}$ at $600 \mathrm{~nm}$ increased from $35 \%$ to $85 \%$ when the carboxyl content of TOCNF went from a value of $1 \mathrm{mmol} \mathrm{g}^{-1}$ to $1.5 \mathrm{mmol} \mathrm{g}^{-1}$. Similarly, Liimatainen et al. showed that $\% \mathrm{~T}$ increased from $50 \%$ to $75 \%$ as the $\mathrm{COOH}$ content of periodate-oxidized $\mathrm{CNF}$ went from 0.38 to $1.75 \mathrm{mmol} \mathrm{g}^{-1} \cdot{ }^{21}$ Hence, the particularly high $\% \mathrm{~T}$ for SCNF suspension $(97 \%$ at $600 \mathrm{~nm}$ ) is attributed to their high $\mathrm{COOH}$ content which results in the repulsion of negatively charged nanofibers limiting their aggregation. In the UV range, the presence of a benzene ring in the structure of PCNF blocks UV light below $290 \mathrm{~nm}$. On the contrary, SCNF display good transparency in both visible and UV range and is therefore potentially interesting in biomedical applications (for UV disinfection) or for optical devices. 

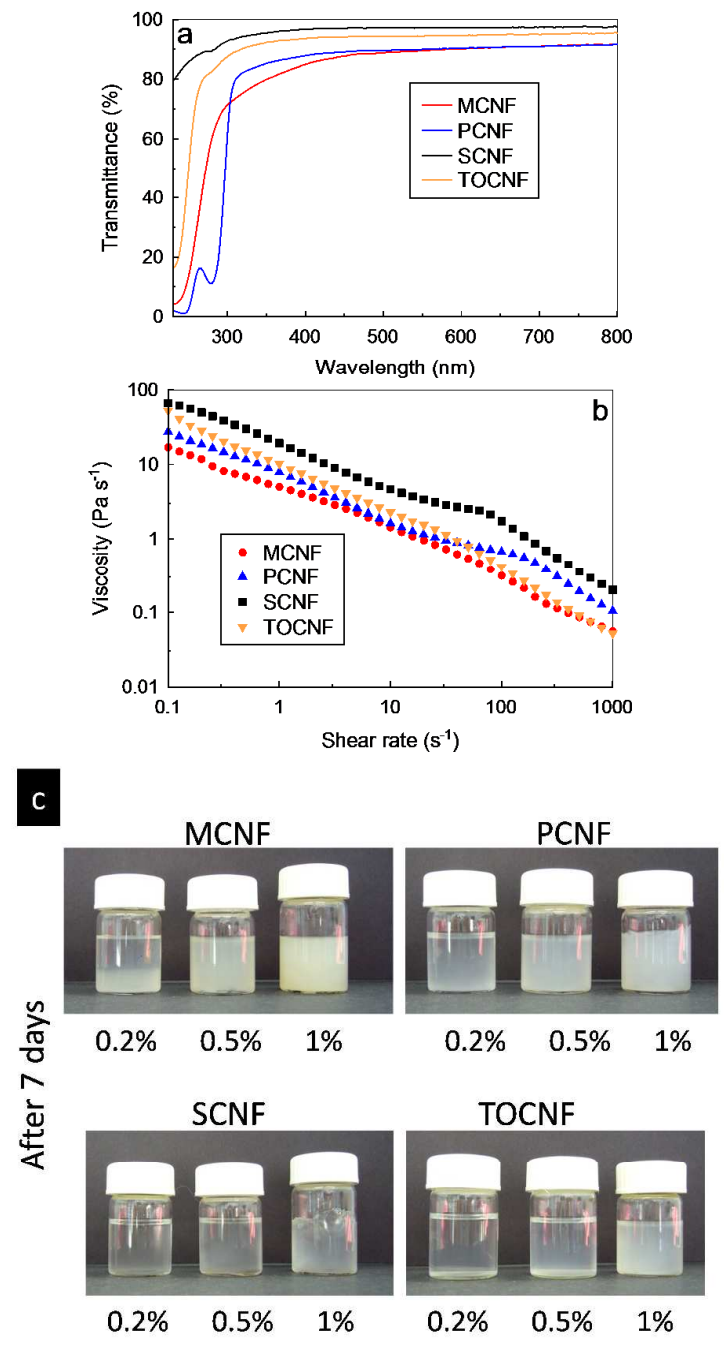

Figure 6. a. UV-Vis transmittance of CNF suspensions at $0.1 \mathrm{wt} \%$. b. viscosity vs shear rate of CNF suspensions at $1 \mathrm{wt} \%$. c. photographs showing CNF suspensions of various concentrations prepared from freeze-dried CNF. Photographs were taken 7 days after redispersion.

Rheological measurements of CNF suspension at $1 \mathrm{wt} \%$ were evaluated using a rheometer with concentric cylinder geometry. All display a shear thinning behavior typical for CNF gels. At low shear rate, the viscosity of the CNF suspension correlates with their carboxyl content (see supporting information S3) and the repulsion of negatively charged fibrils thickens the gel and increases its viscosity. By increasing the shear rate, high shear forces caused the rupture of the CNF network leading to an easy flow of the CNF suspension and a decline in its viscosity. Thus, the sharper decrease in the viscosity of TOCNF occurring at high shear rate indicates 
that entangled network structures in TOCNF are reduced compared to esterified CNF making it more prone to rupture, and this is attributed to the lower $\mathrm{DP}_{\mathrm{v}}$ and aspect ratio of TOCNF as compared to esterified CNF. Generally, the viscosity of CNF suspension depends not only on the shear rate, but on the CNF concentration, aspect ratio, and surface charges. ${ }^{27}$ At a concentration of $1 \mathrm{wt} \%$ and a shear rate of $1 \mathrm{~s}^{-1}$, carboxylated CNF have a viscosity in the range 5-20 Pa s while typical viscosity for low aspect ratio CNC's is $0.1 \mathrm{~Pa}$ s versus a viscosity of 1-10 Pa s for longer aspect ratio CNF (non-carboxylated). ${ }^{4,27}$

It is important to note the facile CNF redispersion after lyophilization (Figure 6.c). Nonflocculate and stable suspensions were achieved by dispersing freeze-dried CNF in water at a concentration of $1 \mathrm{wt} \%$ using sonication. At even lower concentration of $0.5 \mathrm{wt} \%$ and $0.2 \mathrm{wt} \%$, CNF flocculation was only observed for MCNF, PCNF and TOCNF, while highly stable SCNF suspension was achieved even after storage for several months, attesting beneficial effect of carboxyl groups for CNF stabilization via electrostatic repulsion. In contrast, non-modified CNF cannot be redispersed after lyophilisation unless additives such as sodium chloride are used. ${ }^{28}$

In order to show superior performance of highly carboxylated CNF in terms of heavy metal ions removal, we used $5 \mathrm{wt} \%$ of SCNF or TOCNF as additive during the preparation of paper-sheets composed of waste pulp fibers. The concept of using CNF with pulp fibers aimed in previous studies to improve stress-transfer and hence mechanical properties of paper-sheets whereby a CNF network is formed inside the $2 \mathrm{D}$ arranged pulp fibers. ${ }^{29,30}$ In the present work, the prepared composite paper filters were intended to reduce the concentration of lead in solution. When filtering a lead solution with $330 \mu \mathrm{g} \mathrm{L}^{-1}$ of $\mathrm{Pb}$ (II) through a reference paper filter formed solely by waste pulp fibers, the concentration of lead was decreased by $50 \%$ to $165 \mu \mathrm{g} \mathrm{L} \mathrm{L}^{-1}$, and this is attributed to the presence of negative charges in the waste pulp originating from cellulose oxidation during the pulping process. ${ }^{31}$ ${ }^{32,}{ }^{33}$ When introducing $5 \mathrm{wt} \%$ of TOCNF into the filter, the concentration of lead was decreased further to $88 \mu \mathrm{g} \mathrm{L}^{-1}$ (lead removal of $73.5 \%$ ). On the other hand, the concentration of lead in the filtrate was the lowest at $12 \mu \mathrm{g} \mathrm{L} \mathrm{L}^{-1}$ for filters with $5 \mathrm{wt} \% \mathrm{SCNF}$, which is equivalent to a lead removal of $96.5 \%$. Hence, highly carboxylated CNF are more efficient in filters for the removal of HMI 
through adsorption, although CNF addition resulted in a reduced flux of the filter (assessed qualitatively). This is in agreement with batch experiments whereby higher carboxyl content onto CNF resulted in a higher adsorption of copper II ions. ${ }^{9}$ In consequence, for the removal of the same amount of heavy metal ions by CNF-based filters, a smaller content of SCNF is required in the filter as compared to nanofibers with lower carboxyl content and this is economically beneficial. Future studies shall be dedicated to the performance of SCNF filters with various SCNF configurations and contents taking into account their flux and possibility of regeneration. For the aforementioned reasons, we foresee a superior performance of SCNF not only in filter applications for the removal of negatively charged contaminants, but also as a carrier of other functional entities.

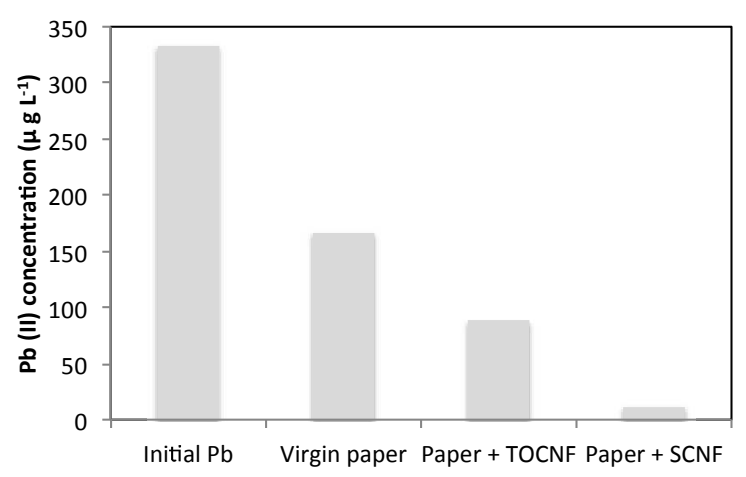

Figure 7. Concentration of $\mathrm{Pb}(\mathrm{II})$ before and after filtration through various filter substrates.

\section{Conclusion}

Wheat fibers were reacted with maleic, phtalic and succinic anhydrides, followed by a high-shear mechanical disintegration using a microfluidizer to yield carboxylated CNF having 4-6 nm in diameter. Amongst these anhydrides, succinic resulted in the highest carboxyl group content of $3.8 \mathrm{mmol} \mathrm{g} \mathrm{g}^{-1}$, which was about 3 times higher than carboxyl content of other nanofibers and the highest ever reported for native cellulose nanofibers. Dynamic molecular simulation revealed a larger number of succinic anhydride molecules in the vicinity of cellulose surfaces while contracting a larger number of hydrogen bonds with them as compared to other anhydrides, and this is a possible reason for the high carboxyl content of SCNF. Consequently, not only primary hydroxyl groups participated in the esterification reaction with succinic anhydride, but also secondary hydroxyl groups located at the surface of the fibrils, resulting in a lower crystallinity of SCNF. The particularly high carboxyl content 
of SCNF has several advantages: 1/ the repulsion of negative charges at the fibrils surfaces considerably facilitated cellulose nanofibers isolation from wheat fibers necessitating only one pass through the microfluidizer, as compared to several passes required for other modifications. $2 /$ the resulting CNF suspension is highly transparent and stable due to limited fibrils aggregation and flocculation, and can be prepared from lyophilized CNF even at a very low concentration. 3/ viscosity of the aqueous CNF suspension is higher, possibly due to swelling of SCNF gel, and this is of interest for SCNF application as rheological modifier of aqueous solutions. 4/ the nanofibers can be implemented in paper filters giving an efficient removal of heavy metal ions from aqueous solutions. Furthermore, the esterification with cyclic anhydrides does not result in a massive reduction in molar mass, as is the case of Tempo-oxidation, and results in a better thermal stability of corresponding nanofibers. We foresee potential applications of SCNF in environmental remediation for the removal of pollutants, as a carrier of functional material or in highly transparent films for packaging, biomedical and electronic applications.

\section{ASSOCIATED CONTENT}

\section{Supporting Information}

Scanning and transmission electron micrographs of carboxylated CNF, and viscosity evolution with the carboxyl content. This material is available free of charge via the Internet at http://pubs.acs.org.

\section{Acknowledgements}

Anja Huch, Esther Strub, Beatrice Fisher, Benjamin Michen and Arndt Remhof are thanked for their support for TEM, DP $\mathrm{v}$, TGA, zeta-potential and XRD analyses, respectively. This work was supported by the European project NanoSelect, FP7 Collaborative project, grant agreement no. 280519 .

\section{References}

1. Turbak, A. F.; Snyder, F. W.; Sandberg, K. R. J. Appl. Polym. Sci. 1983, 37, 815-827.

2. Klemm, D.; Kramer, F.; Moritz, S.; Lindstrom, T.; Ankerfors, M.; Gray, D.; Dorris, A. Angew. Chem., Int. Ed. 2011, 50, 5438-5466. 
3. Henriksson, M.; Henriksson, G.; Berglund, L. A.; Lindstrom, T. Europ. Polym. J. 2007, $43,3434-3441$.

4. Paakko, M.; Ankerfors, M.; Kosonen, H.; Nykanen, A.; Ahola, S.; Osterberg, M.; Ruokolainen, J.; Laine, J.; Larsson, P. T.; Ikkala, O.; Lindstrom, T. Biomacromolecules 2007, 8, 1934-1941.

5. Saito, T.; Kimura, S.; Nishiyama, Y.; Isogai, A. Biomacromolecules 2007, 8, 2485-2491.

6. Habibi, Y. Chem. Soc. Rev. 2014, 43, 1519-1542.

7. Nystrom, G.; Razaq, A.; Stromme, M.; Nyholm, L.; Mihranyan, A. Nano Lett. 2009, 9, $3635-3639$.

8. Sehaqui, H.; Gálvez, M. E.; Becatinni, V.; cheng Ng, Y.; Steinfeld, A.; Zimmermann, T.; Tingaut, P. Environ. Sci. Technol. 2015, 49, 3167-3174.

9. Sehaqui, H.; de Larraya, U.; Liu, P.; Pfenninger, N.; Mathew, A.; Zimmermann, T.; Tingaut, P. Cellulose 2014, 21, 2831-2844.

10. Weishaupt, R.; Siqueira, G.; Schubert, M.; Tingaut, P.; Maniura-Weber, K.; Zimmermann, T.; Thöny-Meyer, L.; Faccio, G.; Ihssen, J. Biomacromolecules 2015, 16, 3640-3650.

11. Pei, A.; Butchosa, N.; Berglund, L. A.; Zhou, Q. Soft Matter 2013, 9, 2047-2055.

12. Fukuzumi, H.; Saito, T.; Wata, T.; Kumamoto, Y.; Isogai, A. Biomacromolecules 2009, $10,162-165$.

13. Koga, H.; Saito, T.; Kitaoka, T.; Nogi, M.; Suganuma, K.; Isogai, A. Biomacromolecules 2013, $14,1160-1165$.

14. Ma, H. Y.; Hsiao, B. S.; Chu, B. ACS Macro Lett. 2012, 1, 213-216.

15. Ma, H. Y.; Burger, C.; Hsiao, B. S.; Chu, B. Biomacromolecules 2012, 13, 180-186.

16. Saito, T.; Hirota, M.; Tamura, N.; Kimura, S.; Fukuzumi, H.; Heux, L.; Isogai, A. Biomacromolecules 2009, 10, 1992-1996.

17. Henriksson, M.; Berglund, L. A.; Isaksson, P.; Lindstrom, T.; Nishino, T. Biomacromolecules 2008, 9, 1579-1585.

18. Iwamoto, S.; Endo, T. ACS Macro Lett. 2015, 4, 80-83. 
19. Saito, T.; Nishiyama, Y.; Putaux, J. L.; Vignon, M.; Isogai, A. Biomacromolecules 2006, 7, 1687-1691.

20. Okita, Y.; Saito, T.; Isogai, A. Biomacromolecules 2010, 11, 1696-1700.

21. Liimatainen, H.; Visanko, M.; Sirviö, J. A.; Hormi, O. E. O.; Niinimaki, J. Biomacromolecules 2012, 13, 1592-1597.

22. Leung, A. C. W.; Hrapovic, S.; Lam, E.; Liu, Y.; Male, K. B.; Mahmoud, K. A.; Luong, J. H. T. Small 2011, 7, 302-305.

23. French, A. D. Cellulose 2014, 21, 885-896.

24. Shinoda, R.; Saito, T.; Okita, Y.; Isogai, A. Biomacromolecules 2012, 13, 842-849.

25. Lin, Y.-C.; Cho, J.; Tompsett, G. A.; Westmoreland, P. R.; Huber, G. W. J. Phys. Chem. C 2009, 113, 20097-20107.

26. Chen, L.; Zhu, J. Y.; Baez, C.; Kitin, P.; Elder, T. Green Chem. 2016, 18, 3835-3843.

27. Li, M.-C.; Wu, Q.; Song, K.; Lee, S.; Qing, Y.; Wu, Y. ACS Sustainable Chem. Eng. 2015, 3, 821-832.

28. Missoum, K.; Bras, J.; Belgacem, M. N. Biomacromolecules 2012, 13, 4118-4125.

29. Sehaqui, H.; Allais, M.; Zhou, Q.; Berglund, L. A. Compos. Sci. Technol. 2011, 71, 382387.

30. Sehaqui, H.; Zhou, Q.; Berglund, L. Nord. Pulp Pap. Res. J. 2013, 28, 182-189.

31. Liu, P.; Sehaqui, H.; Tingaut, P.; Wichser, A.; Oksman, K.; Mathew, A. Cellulose 2014, $21,449-461$.

32. Sehaqui, H.; Perez de Larraya, U.; Tingaut, P.; Zimmermann, T. Soft Matter 2015, 11, 5294-5300.

33. Olszewska, A.; Eronen, P.; Johansson, L. S.; Malho, J. M.; Ankerfors, M.; Lindstrom, T.; Ruokolainen, J.; Laine, J.; Osterberg, M. Cellulose 2011, 18, 1213-1226.

34. Sehaqui, H.; Zhou, Q.; Ikkala, O.; Berglund, L. A. Biomacromolecules 2011, 12, 36383644 .

35. Segal, L.; Creely, J. J.; Martin, A. E.; Conrad, C. M. Text. Res. J. 1959, 29, 786-794.

36. Nelson, M.; O'Connor, R. J. Appl. Polym. Sci. 1964, 8, 1325-1341. 
37. Katz, S.; Beatson, R. P.; Scallan, A. M. Svensk Papperstidn 1984, 87, 48-53.

38. Smith, D. K.; Bampton, R. F.; Alexander, W. J. Ind. Eng. Chem. Process Des. Dev. 1963, 2, 57-62.

39. Malde, A. K.; Zuo, L.; Breeze, M.; Stroet, M.; Poger, D.; Nair, P. C.; Oostenbrink, C.; Mark, A. E. J. Chem. Theory Comput. 2011, 7, 4026-4037.

40. Gomes, T. C. F.; Skaf, M. S. J. of Computat. Chem. 2012, 33, 1338-1346.

41. Nishiyama, Y.; Langan, P.; Chanzy, H. J. Am. Chem. Soc. 2002, 124, 9074-9082.

42. Jonoobi, M.; Mathew, A. P.; Oksman, K. Ind. Crops Prod. 2012, 40, 232-238.

43. Sehaqui, H.; Michen, B.; Marty, E.; Schaufelberger, L.; Zimmermann, T. ACS Sustainable Chem. Eng. 2016, 4, 4582-4590.

44. Galland, S.; Berthold, F.; Prakobna, K.; Berglund, L. A. Biomacromolecules 2015, 16, $2427-2435$.

45. Su, Y.; Burger, C.; Ma, H. Y.; Chu, B.; Hsiao, B. S. Biomacromolecules 2015, 16, 12011209.

46. Willför, S.; Pranovich, A.; Tamminen, T.; Puls, J.; Laine, C.; Suurnäkki, A.; Saake, B.; Uotila, K.; Simolin, H.; Hemming, J.; Holmbom, B. Ind. Crops Prod. 2009, 29, 571-580. 